\title{
Association of the leptin-to-adiponectin ratio with metabolic syndrome in a sub-Saharan African population
}

\author{
Clarisse Noël A. Ayina ${ }^{1}$, Francky Teddy A. Endomba2* , Samuel Honoré Mandengue ${ }^{1}$, Jean Jacques N. Noubiap, \\ Laurent Serge Etoundi Ngoa ${ }^{4}$, Philippe Boudou ${ }^{5}$, Jean-François Gautier ${ }^{6,7}$, Jean Claude Mbanya ${ }^{2,8,9}$ \\ and Eugene Sobngwi $i^{2,8,9}$
}

\begin{abstract}
Background: Worldwide there is an increased prevalence of metabolic syndrome mainly due to life-style modifications, and Africans are not saved of this situation. Many markers have been studied to predict the risk of this syndrome but the most used are leptin and adiponectin. Data on these metabolic markers are scare in Africa and this study aimed to assess the association between the leptin-to-adiponectin ratio (LAR) with metabolic syndrome in a Cameroonian population.

Methods: This was a cross-sectional study that included 476 adults among a general population of Cameroon. Data collected concerned the body mass index, waist circumference, systolic blood pressure, diastolic blood pressure, fasting blood glucose, plasma lipids, adiponectin, leptin, insulin and homeostasis model for assessment of insulin resistance (HOMA-IR). To assess correlations we used Spearman's analyses and association of the studied variables with metabolic syndrome were done using binary logistic regression analysis.

Results: The leptin to adiponectin ratio was significantly and positively correlated with the body mass index $(r=0.669, p<0.0001)$, waist circumference $(r=0.595, p<0.0001)$, triglycerides $(r=0.190, p=0.001)$, insulin levels $(r=0.333, p<0.0001)$ and HOMA-IR $(r=0.306, p<0.0001)$. Binary logistic regression analysis revealed that leptin, adiponectin and LAR were significantly associated with metabolic syndrome with respective unadjusted OR of 1.429, 0.468 and 1.502. After adjustment, for age and sex, the associations remained significative; LAR was also found to be significantly associated with metabolic syndrome $(O R=1.573, p$ value $=0.000)$ as well as lower levels of adiponectin $(\mathrm{OR}=0.359$, $\mathrm{p}$ value $=0.000)$ and higher levels of leptin $(\mathrm{OR}=1.469, \mathrm{p}$ value $=0.001)$.
\end{abstract}

Conclusion: This study revealed that LAR is significantly associated with metabolic syndrome in sub-Saharan African population, independently to age and sex.

Keywords: Adiponectin, Leptin, Leptin-to-adiponectin ratio, Metabolic syndrome

\section{Background}

There is a surge in the global prevalence of metabolic syndrome and its components including obesity, insulin resistance, diabetes mellitus, dyslipidemia and hypertension, as a result of reduced physical activity and

${ }^{*}$ Correspondence: tedissimo@yahoo.com

${ }^{2}$ Department of Internal Medicine and Specialties, Faculty of Medicine and Biomedical Science, University of Yaoundé I, Yaoundé, Cameroon

Full list of author information is available at the end of the article unhealthy diet [1-4].The burden of metabolic syndrome has been rising over the past decade in African populations, driven by urbanization, sedentarity and nutritional transition [5-7]. To assess people at risk for the development of metabolic syndrome, several markers have been studied, with the large majority of them related to the adipose tissue [3-6]. Two markers are of particular interest, adiponectin and leptin, which are strongly associated to cardiometabolic health or disease $[1,3,7,8]$. For instance, in obese patients who are at risk of insulin 
resistance and thus metabolic syndrome, secretion of adiponectin by hypertrophic adipocytes is reduced, while that of leptin is increased [12-14]. Indeed, leptin and adiponectin levels have been found to be respectively positively and negatively correlated with obesity, diabetes mellitus, hypertension and metabolic syndrome [12-15]. Leptin and adiponectin also have opposite's effects on inflammatory markers and thus subclinical inflammation [9]. Leptin is considered as a proinflammatory cytokine since it up regulates pro-inflammatory cytokines such as TNF- $\alpha$ and IL-6 [9-11]. On the contrary, adiponectin displays anti-inflammatory properties by down regulation of the expression and release of proinflammatory mediators [9, 12-14].

Recent studies have demonstrated in the potential of the leptin-to-adiponectin ratio (LAR) as a novel predictor of cardio-metabolic outcomes including metabolic syndrome [3, 15-17]. LAR has been shown to be associated with insulin resistance, metabolic syndrome, carotid intima-media thickness, "at-risk phenotype" in young severely obese patients, and chronic kidney disease, among others [18-20]. Some others studies found this marker to be a better tool for the diagnosis of metabolic syndrome and risk stratification of subjects, than adiponectin or leptin alone $[15,16,21]$. In a recent study we demonstrated that leptin and adiponectin correlate to surrogates of obesity, blood lipids and insulin resistance in sub-Saharan Africans [22]. The current study aimed investigates the association of LAR with metabolic syndrome in a group of Cameroonians.

\section{Methods}

\section{Study population}

This is a cross-sectional study conducted in May 2010 in Douala and Edéa, two urban cities of the Littoral region of Cameroon. The study population consisted of individuals of both sex aged $\geq 18$ years from the general population, who accepted to participate in the study after an invitation through radio announcements. Pregnant and breast-feeding women, as well as subjects with serious chronic illness, or ongoing or recent $(<10$ days $)$ acute illness, or those taking any current medication were excluded from the study. After applying the exclusion criteria, 476 participants were included in the study.

\section{Data collection}

For each subject, weight was measured in light clothes with a seca scale balance to the nearest $0.1 \mathrm{~kg}$, height with a calibrated stadiometer, waist circumference (WC) at midway between the lowest rib and the iliac crest and hip circumference at the outermost points of the greater trochanters to the nearest $0.5 \mathrm{~cm}$ and waist-to-hip ratio
(WHR) as waist circumference divided by hip circumference. Body mass index (BMI) was calculated using the Quetelet's formula as weight (in $\mathrm{kg}$ ) divided by height (in $\mathrm{m}^{2}$ ). We measured resting blood pressures twice using standardized procedures with the participant in a seated position, and after at least $10 \mathrm{~min}$ rest with a validated automated blood pressure measuring device, the Omron HEM-757 (Omron Corporation, Tokyo, Japan). The mean of two measures performed at least $3 \mathrm{~min}$ apart was used for all analyses. Percentage body fat (\%BF) was measured by bioelectric impedance analysis using the OMRON BF 302 (OMRON Matsusaka Co., Tokyo, Japan). After 8-12 h overnight fast, blood glucose was measured between 7 and 10 a.m. using the Accu-Chek ${ }^{\circledR}$ compact plus glucometer (F. Hoffmann-La Roche AG, Basel, Switzerland) on total fresh capillary blood samples, and venous blood samples were obtained from an antecubital vein. Serum was then separated and stored at $-20^{\circ} \mathrm{C}$ for lipid measurements and at $-80{ }^{\circ} \mathrm{C}$ for further biochemical analysis. Serum lipids were analyzed within 1 week after the collection. Serum cholesterol (TC) (cholesterol oxidase phenol 4-amino antipyrine peroxidase method), serum triglycerides (TG) (glycerol phosphatase oxidase-phenol4-amino antipyrine peroxidase method), and high-density lipoprotein-cholesterol (HDL-c) (cholesterol oxidase phenol4-amino antipyrine peroxidase method) were measured on a spectrophotometer (UV mini 1240) using Chronolab kits (Chronolab Systems, Barcelona, Spain). Low-density lipoprotein-cholesterol (LDL-c) was calculated using the Friedwald's formula. Insulin levels were measured using an electrochemiluminescence immunoassay (Roche Diagnostics, Indianapolis, USA), while serum leptin and adiponectin were measured by radio immuno assay (RIA) using Linco Research kits (Linco Research Inc., St Charles, Missouri, USA) with the following characteristics: Adiponectin assay coefficient of variation $(\mathrm{CV}) \leq 10 \%$; detection limit of $2 \mathrm{ng} /$ $\mathrm{mL}$ for $100 \mu \mathrm{l}$ sample size; a linearity range of $500 \mathrm{ng} / \mathrm{mL}$ for $100 \mu \mathrm{L}$ sample size. Leptin assay's coefficient of variation $\leq 10 \%$ (intra-assay's CV $\leq 8.3 \%$ and inter assay's CV $\leq 6.2 \%$ ); a detection limit of $0.5 \mathrm{ng} / \mathrm{mL}$ for $100 \mu \mathrm{L}$ sample size; a linearity range of $100 \mathrm{ng} / \mathrm{mL}$ for $100 \mu \mathrm{L}$ sample size. Anthropometrical and biochemical measurements was made once on each participant.

Homeostasis model assessment of insulin resistance (HOMA-IR) as

$$
\begin{aligned}
\mathrm{HOMA}-\mathrm{IR}= & \left(\text { Fasting insulin }\left(\mu \frac{\mathrm{UI}}{\mathrm{mL}}\right)\right. \\
& \left.\times \text { Fasting blood glucose }\left(\frac{\mathrm{Mmol}}{\mathrm{L}}\right)\right) \div 22.5
\end{aligned}
$$




\section{Definition of anthropomorphic indices of obesity}

According to the World Health Organization guidelines, obesity was defined as BMI $\geq 30 \mathrm{~kg} / \mathrm{m}^{2}$ [23], WC $>94 \mathrm{~cm}$ in men and $>80 \mathrm{~cm}$ in women, WHR $\geq 0.90$ in men and $\geq 0.85$ in women [24]. The BF\% cutoffs chosen to define obesity were the values most frequently cited by international scientific literature: $\mathrm{BF} \% \geq 25$ for men and $\geq 35$ for women [25].

\section{Definition of metabolic syndrome}

The metabolic syndrome was defined using, the IDF/ AHA/NHLBI consensus harmonized definition published by Alberti et al. in 2009 [26], that recommends three or more of any of the following criteria: WC $\geq 80 \mathrm{~cm}$ (women) $\geq 94 \mathrm{~cm}$ (men), $\mathrm{SBP} \geq 130 \mathrm{mmHg}$ and/ or DBP $\geq 85 \mathrm{mmHg}$, or blood pressure lowering treatment, fasting plasma glucose $\geq 5.6 \mathrm{mmol} / \mathrm{L}[101 \mathrm{mg} /$ $\mathrm{dL}$, or anti diabetic treatment, fasting triglycerides $>1.70 \mathrm{mmol} / \mathrm{L}[154.5 \mathrm{mg} / \mathrm{dL}]$ or triglyceride lowering drugs and HDL-c $<1 \mathrm{mmol} / \mathrm{L}[40 \mathrm{mg} / \mathrm{dL}]$ (women) $<1.3 \mathrm{mmol} / \mathrm{L}$ [52 mg/dL] (men).

\section{Statistical analysis}

Data were coded, entered and analyzed using the statistical package for social science (SPSS) version 20.0 for Windows (IBM Corp. Released 2011. IBM SPSS statistics for windows, version 20.0. Armonk, NY: IBM Corp.). The distribution pattern of the variables was checked. Normally distributed variables are expressed as mean with standard deviation (SD). Skewed variables are reported as median (interquartile range). Skewed variables were $\log$ transformed. The L/A ratios are expressed as the absolute value of plasma leptin $(\mathrm{ng} / \mathrm{mL})$ divided by the absolute value of plasma adiponectin $(\mu \mathrm{g} / \mathrm{mL})$. The independent sample $t$ test was used to compare clinical and biological parameters between men and women. Spearman's correlations were used to determine correlates of leptin and adiponectin serum levels, as well as LAR's. Binary logistic regression analysis included adiponectin, leptin and LAR as dependent variables, and were used to identify independent factors able to predict metabolic syndrome after adjustment for age, sex and BMI. Statistical tests are two tailed. A $p$ value $<0.05$ was considered statistically significant.

\section{Ethical considerations}

This study was performed in accordance with the guidelines of the Helsinki declaration and was approved by the national ethics committee for human health research and by the ministry of public health of Cameroon. Written informed consent was obtained from all participants.

\section{Results}

Clinical and metabolic characteristics of the study population

A total of 476 subjects (167 men and 309 women) were enrolled in the study. The median age (interquartile) was 55.0 (23.6) for men and 50.0 (20.0) for women $(p<0.05)$. WHR, SBP and DBP were significantly higher in men $(p<0.05$ respectively). Triglycerides, LDL-c, insulin, adiponectin, leptin, and HOMA-IR were significantly higher in women $(p<0.05$ respectively) (Table 1$)$.

\section{Correlations between leptin-to-adiponectin ratio and anthropometric indexes of obesity, blood pressure, blood lipids and insulin resistance}

As represented in Table 2, leptin-to-adiponectin ratio was significantly and positively correlated with body mass index $(\mathrm{r}=0.669, \mathrm{p}<0.0001)$, waist circumference $(r=0.595, p<0.0001)$, triglycerides $(r=0.190$, $\mathrm{p}=0.001)$, insulin levels $(\mathrm{r}=0.333, \mathrm{p}<0.0001)$ and HOMA-IR ( $r=0.306, p<0.0001)$. There was no significant correlation within LAR and systolic or diastolic blood pressure, glycaemia and HDL cholesterol.

\section{Association between leptin-to-adiponectin ratio and metabolic syndrome}

Binary logistic regression analysis (see Table 3) metabolic syndrome was significantly associated with higher levels of leptin $(\mathrm{OR}=1.42$, p value $=0.003)$ as well as with lower levels of adiponectin $(\mathrm{OR}=0.46$, $\mathrm{p}$ value $=0.001$ ) and LAR $(\mathrm{OR}=1.5$, p value $<0.0001)$. After adjustment for age and sex, the LAR was also found to be significantly associated with metabolic syndrome $(\mathrm{OR}=1.573$, $\mathrm{p}$ value $=0.000$ ) as well as lower levels of adiponectin $(\mathrm{OR}=0.359, \mathrm{p}$ value $=0.000)$ and higher levels of leptin $(\mathrm{OR}=1.469$, $\mathrm{p}$ value $=0.001)$.

\section{Discussion}

It's nowadays accepted that adipokines mostly leptin and adiponectin, play an important role in many physiological pathways including glucose metabolism through insulin regulation $[4,27]$. It has been demonstrated that these molecules can be predictive of metabolic syndrome. Indeed lower adiponectin levels have been found to be significantly associated with metabolic syndrome $[1,3,7,8]$. In the other hand, metabolic syndrome is found to be associated with higher levels of leptin. Even though these markers are well described in literature, some recent findings revealed the possible role of leptinto-adiponectin ratio in the prediction of cardiometabolic diseases including metabolic syndrome [3, 15-17]. This study was conducted to so assess the relationship of LAR with some anthropometric indexes, blood lipids, blood 
Table 1 Clinical and metabolic characteristics of the study population)

\begin{tabular}{|c|c|c|c|}
\hline & Men $(n=167)$ & Women ( $n=309$ ) & $p$ value \\
\hline Age & $55 \pm 23$ & $50 \pm 20$ & $<0.0001$ \\
\hline Weight (kg) & $71.00 \pm 23.00$ & $70.00 \pm 25.00$ & 0.984 \\
\hline Height (m) & $1.70 \pm 0.20$ & $1.60 \pm 0.10$ & $<0.0001$ \\
\hline $\mathrm{BMI}\left(\mathrm{kg} / \mathrm{m}^{2}\right)$ & $25.30 \pm 6.30$ & $28.00 \pm 6.60$ & $<0.0001$ \\
\hline WC (cm) & $91.04 \pm 12.6$ & $93.58 \pm 14.0$ & 0.091 \\
\hline WHR (cm) & $0.91 \pm 0.09$ & $0.87 \pm 0.09$ & $<0.0001$ \\
\hline $\mathrm{BF}(\%)$ & $22.90 \pm 8.62$ & $34.00 \pm 10.42$ & $<0.0001$ \\
\hline $\mathrm{SBP}(\mathrm{mm} \mathrm{Hg})$ & $137 \pm 37$ & $128 \pm 33$ & $<0.0001$ \\
\hline $\mathrm{DBP}(\mathrm{mm} \mathrm{Hg})$ & $86 \pm 21$ & $82 \pm 20$ & 0.006 \\
\hline Blood glucose (mmol/L) [mg/dL] & $5.0 \pm 1.10[90.9 \pm 20]$ & $4.80 \pm 1.15[87.3 \pm 20.9]$ & 0.204 \\
\hline Total cholesterol (mmol/L) [mg/dL] & $4.14 \pm 1.07[165.6 \pm 42.8]$ & $4.45 \pm 1.16[178 \pm 46.4]$ & 0.05 \\
\hline Triglycerides (mmol/L) [mg/dL] & $1.20 \pm 0.45[109.9 \pm 40.9]$ & $1.26 \pm 0.35[114.5 \pm 31.8]$ & 0.024 \\
\hline LDL-c (mmol/L) [mg/dL] & $1.48 \pm 0.97[59.2 \pm 38.8]$ & $1.78 \pm 1.17[71.2 \pm 46.8]$ & 0.031 \\
\hline $\mathrm{HDL}-\mathrm{c}(\mathrm{mmol} / \mathrm{L})[\mathrm{mg} / \mathrm{dL}]$ & $2.13 \pm 0.99[85.2 \pm 39.6]$ & $2.14 \pm 0.91[85.6 \pm 36.4]$ & 0.763 \\
\hline Insulin $(\mu \mathrm{U} / \mathrm{mL})$ & $2.14 \pm 2.16$ & $2.73 \pm 2.47$ & 0.020 \\
\hline HOMA-IR & $8.64 \pm 0.25$ & $11.05 \pm 11.13$ & 0.031 \\
\hline Adiponectin $(\mu \mathrm{g} / \mathrm{mL})$ & $7.65 \pm 5.55$ & $10.75 \pm 8.90$ & 0.038 \\
\hline Leptin (ng/mL) & $4.80 \pm 6.20$ & $18.50 \pm 24.40$ & $<0.0001$ \\
\hline
\end{tabular}

WC values are means (standard deviation); except for WC, values are median (interquartile range)

WC waist circumference, $B F \%$ body fat percentage, $B M I$ body mass index, WHR waist-hip ratio, SBP systolic blood pressure, $D B P$ diastolic blood pressure, $L D L-C$ low density lipoprotein-cholesterol, HDL-c high density lipoprotein-cholesterol, HOMA-IR homeostasis model assessment of insulin resistance

Table 2 Pearson's correlation of adiponectin, leptin and LAR with parameters of metabolic syndrome

\begin{tabular}{|c|c|c|c|c|c|c|}
\hline & Adipone & & Leptin & & LAR & \\
\hline & $\mathbf{R}$ & $p$ & $\mathbf{R}$ & $P$ & $r$ & $p$ \\
\hline IMC $\left(\mathrm{kg} / \mathrm{m}^{2}\right)$ & $-0.297^{*}$ & 0.000 & $0.649^{*}$ & 0.000 & $0.669^{*}$ & 0.000 \\
\hline WC (cm) & $-0.297^{*}$ & 0.000 & $0.560^{*}$ & 0.000 & $0.595^{*}$ & 0.000 \\
\hline $\mathrm{SBP}(\mathrm{mm} \mathrm{Hg})$ & 0.013 & 0.820 & 0.045 & 0.416 & 0.034 & 0.537 \\
\hline $\mathrm{DBP}(\mathrm{mm} \mathrm{Hg})$ & -0.005 & 0.921 & $0.116^{*}$ & 0.036 & 0.099 & 0.073 \\
\hline Blood glucose (mmol/L) & -0.042 & 0.443 & -0.014 & 0.797 & 0.013 & 0.814 \\
\hline $\mathrm{TG}(\mathrm{mmol} / \mathrm{L})$ & $-0.140^{*}$ & 0.011 & $0.150^{*}$ & 0.007 & $0.190^{*}$ & 0.001 \\
\hline $\mathrm{HDL}-\mathrm{c}(\mathrm{mmol} / \mathrm{L})$ & 0.095 & 0.087 & -0.012 & 0.833 & -0.058 & 0.296 \\
\hline Insulin ( $\mu \mathrm{U} / \mathrm{mL})$ & -0.123 & 0.059 & $0.332^{*}$ & 0.000 & $0.333^{*}$ & 0.000 \\
\hline HOMA-IR & $-0.139^{*}$ & 0.032 & $0.288^{*}$ & 0.000 & $0.306^{*}$ & 0.000 \\
\hline
\end{tabular}

WC waist circumference, $B M I$ body mass index, SBP systolic blood pressure, $D B P$ diastolic blood pressure, $T G$ triglycerides, $H D L-c$ high density lipoprotein-cholesterol, HOMA-IR homeostasis model assessment of insulin resistance, * Significant correlation

Table 3 Unadjusted and adjusted (for age and sex) ORs (95\% CI) for metabolic syndrome according to log-transformed leptin, adiponectin and LAR, by binary logistic regression analysis

\begin{tabular}{lllll}
\hline Variables & \multicolumn{4}{l}{ Metabolic syndrome } \\
\cline { 2 - 5 } & Unadjusted OR (CI) & $\boldsymbol{p}$ & Adjusted OR (CI) & $\boldsymbol{p}$ \\
\hline Leptin & $1.429(1.134-1.802)$ & 0.003 & $1.469(1.16-1.86)$ & 0.001 \\
Adiponectin & $0.468(0.304-0.720)$ & 0.001 & $0.359(0.225-0.573)$ & 0.000 \\
LAR & $1.502(1.231-1.833)$ & 0.000 & $1.573(1.281-1.932)$ & 0.000 \\
\hline
\end{tabular}

pressure and insulin resistance among a sub-Saharan African population.

Our study revealed a positive correlation of LAR to body mass index, waist circumference, triglycerides and insulin resistance. These findings are similar to those of Kotani et al. [28] in a study that involved 678 non-smoking Japanese subjects. The authors found that the LAR was significantly and positively associated with components of metabolic syndrome including BMI and triglycerides, especially in men. Nevertheless, contrary to them, 
no significant correlation was found between glucose levels and LAR. Zyl et al. [29] found similar results in their study on South African urban women, although LAR was significantly higher in women with elevated blood glucose. This finding seems to be specific to Africans. In the literature, it has been proved that LAR is associated with increased waist circumference and also decreased vascular response to acetylcholine $[9,15]$. Also, the LAR has been found to be associated with an increased vasoconstrictive response to angiotensin II [30].

With and without adjustment for age and sex, metabolic syndrome was significantly associated with LAR, leptin and adiponectin. Thus the LAR levels were significantly higher in metabolic syndrome subjects than in non metabolic syndrome, as well as the levels of leptin. Meanwhile, adiponectin levels were significantly lower in subjects with metabolic syndrome. These results look like those of Kotani et al. [28] who found that LAR was significantly higher in peoples with metabolic syndrome, even when adjusted for sex. Zhuo et al. [16] in a study that involved 950 males and 1096 females aged between 60 and 96 years; found that LAR, as well as leptin, may be better markers than adiponectin for the diagnosis of metabolic syndrome. Also, the authors found that LAR has better capacity in the classification of subjects with and without metabolic syndrome than adiponectin or leptin alone. Many others studies have noticed the function of LAR as a good marker of obesity, diabetes mellitus, insulin resistance and metabolic syndrome compared to adiponectin or leptin alone $[6,19,21]$. LAR has also been found to be related to low grade inflammation and insulin resistance independently of obesity, with a more powerful association with CRP and HOMA-IR than leptin or adiponectin alone [6,31]. Our study has a principal strength that this population was not receiving potentially confounding medications during the investigation. Nevertheless, this study has two main limitations. First, its cross-sectional design prevented us from identifying cause-and-effect associations LAR and MS. Secondly, we used HOMA-IR to evaluate insulin sensitivity rather than gold-standard methods such as the hyperinsulinemic euglycemic clamp and the frequently sampled intravenous glucose tolerance test which, however, would have been significantly very difficult to perform in such a population-based study in a resource-limited setting. Despite these limitations, our study appears to be the first of this type among a sub-Saharan African population, and noted the possible role of LAR as a diagnostic marker of MS in black Africans peoples.

\section{Conclusion}

In this study higher levels of LAR have been found to be significantly associated with metabolic syndrome as well as higher levels of leptin and lowered ones of adiponectin. Thus, studies with appropriate design must be carried out to really assess whether LAR can be a predictive factor of metabolic syndrome or not, independently of confounding factors.

\section{Abbreviations}

BF\%: percent body fat; BMI: body mass index; CRP: C-reactive protein; HDL-C: high-density lipoprotein cholesterol; HOMA-IR: homeostasis model for assessment of insulin resistance; IL: interleukin; LAR: leptin-to-adiponectin ratio; LDL-c: low-density lipoprotein cholesterol; TC: total cholesterol; TG: triglycerides; TNF-a: tumor necrosis factor alpha; WC: waist circumference; WHR: waist-to-hip ratio.

\section{Authors' contributions}

Study conception and design: CNAA, PB, LSEN, SHM, JFG, JCM, ES. Data collection: CNAA, PB, ES. Statistical analysis and interpretation: CNAA, JJNN, FTAE. Drafting: JJNN, CNAA, FTAE. Critical discussion and manuscript revision: CNAA, FTAE, SHM, JJNN,ES, PB, LSEN, JCM, JFG. All authors read and approved the final manuscript.

\section{Author details \\ ${ }^{1}$ Department of Animal Science, Faculty of Science, University of Douala, Douala, Cameroon. ${ }^{2}$ Department of Internal Medicine and Specialties, Faculty of Medicine and Biomedical Science, University of Yaoundé I, Yaoundé, Cam- eroon. ${ }^{3}$ Department of Medicine, Groote Schuur Hospital, University of Cape Town, Cape Town, South Africa. ${ }^{4}$ Department of Animal Science, Higher Teacher's Training College, University of Yaoundé I, Yaounde, Cameroon. ${ }^{5}$ Department of Hormonal Biology, Saint-Louis Hospital, Public Assistance -Paris Hospitals, University Paris-Diderot Paris-7, Paris, France. ${ }^{6}$ Department of Diabetes and Endocrinology, Lariboisiere Hospital, Public Assistance - Paris Hospitals, University Paris-Diderot Paris-7, Paris, France. ${ }^{7}$ INSERM UMRS 1138 , Cordeliers Research Centre, University Pierre et Marie Curie-Paris 6, Paris, France. ${ }^{8}$ Laboratory for Molecular Medicine and Metabolism, Biotechnology Center, University of Yaoundé I, Yaoundé, Cameroon. ${ }^{9}$ National Obesity Center, Yaoundé Central Hospital, Yaoundé, Cameroon.}

\section{Acknowledgements}

We are grateful to all the volunteers who participated in the study.

\section{Competing interests}

The authors declare that they have no competing interests.

\section{Ethics approval and consent to participate}

The authors attest that the present study was approved by the National Ethics Committee for Human Health Research and by the Ministry of Public Health of Cameroon. Written informed consent was obtained from all participants.

\section{Funding}

This study was funded by the Service of Action and Cooperation of the French embassy in Cameroon.

\section{Publisher's Note}

Springer Nature remains neutral with regard to jurisdictional claims in published maps and institutional affiliations.

Received: 6 March 2017 Accepted: 29 August 2017

Published online: 05 September 2017 


\section{References}

1. Kaur J. A comprehensive review on metabolic syndrome. Cardiol Res Pract. 2014:2014:943162.

2. Han TS, Lean ME. A clinical perspective of obesity, metabolic syndrome and cardiovascular disease. JRSM Cardiovasc Dis. 2016:5. http://www. ncbi.nlm.nih.gov/pmc/articles/PMC4780070/. Accessed 27 Nov 2016.

3. Srikanthan K, Feyh A, Visweshwar H, Shapiro JI, Sodhi K. Systematic review of metabolic syndrome biomarkers: a panel for early detection, management, and risk stratification in the West Virginian population. Int J Med Sci. 2016;13(1):25-38.

4. Grundy SM. Metabolic syndrome update. Trends Cardiovasc Med. 2016;26(4):364-73.

5. Dallmeier D, Larson MG, Vasan RS, Keaney JF, Fontes JD, Meigs JB, et al. Metabolic syndrome and inflammatory biomarkers: a community-based cross-sectional study at the Framingham heart study. Diabetol Metab Syndr. 2012;4:28.

6. Al-Hamodi Z, AL-Habori M, Al-Meeri A, Saif-Ali R. Association of adipokines, leptin/adiponectin ratio and C-reactive protein with obesity and type 2 diabetes mellitus. Diabetol Metab Syndr. 2014;6. http://www.ncbi. nlm.nih.gov/pmc/articles/PMC4177707/. Accessed 17 Nov 2016.

7. Zhang J, Kho P, Ov K, Chenghe S. Adiponectin, Resistin and Leptin: Possible Markers of Metabolic Syndrome. Endocrinol Metab Syndr. http://www.omicsonline.org/open-access/adiponectin-resistin-and leptin-possible-markers-of-metabolic-syndrome-2161-1017-1000212. php?aid=66029. Accessed 28 Nov 2016.

8. Rasmussen-Torvik LJ, Wassel CL, Ding J, Carr J, Cushman M, Jenny N, et al. Associations of BMI and insulin resistance with leptin, adiponectin, and the leptin to adiponectin ratio across ethnic groups: the multi-ethnic study of atherosclerosis (MESA). Ann Epidemiol. 2012;22(10):705-9.

9. López-Jaramillo P, Gómez-Arbeláez D, López-López J, López-López C, Martínez-Ortega J, Gómez-Rodríguez A, et al. The role of leptin/adiponectin ratio in metabolic syndrome and diabetes. Horm Mol Biol Clin Investig. 2014;18(1):37-45.

10. Paz-Filho G, Mastronardi C, Franco CB, Wang KB, Wong M-L, Licinio J. Leptin: molecular mechanisms, systemic pro-inflammatory effects, and clinical implications. Arq Bras Endocrinol Amp Metabol. 2012;56(9):597-607.

11. likuni N, Lam QLK, Lu L, Matarese G, La Cava A. Leptin and Inflammation. Curr Immunol Rev. 2008:4(2):70-9.

12. Fantuzzi G. Adiponectin and inflammation: consensus and controversy. J Allergy Clin Immunol. 2008;121(2):326-30.

13. Mangge $H$, Almer G, Truschnig-Wilders M, Schmidt A, Gasser R, Fuchs D. Inflammation, adiponectin, obesity and cardiovascular risk. Curr Med Chem. 2010;17(36):4511-20

14. Robinson K, Prins J, Venkatesh B. Clinical review: adiponectin biology and its role in inflammation and critical illness. Crit Care. 2011;15:221.

15. Lopez-Jaramillo P. SSA 04-3 leptin/adiponectin in cardiometabolic disease. J Hypertens. 2016;34(Suppl 1-ISH 2016 Abstract Book):e7.

16. Zhuo Q, Wang Z, Fu P, Piao J, Tian Y, Xu J, et al. Comparison of adiponectin, leptin and leptin to adiponectin ratio as diagnostic marker for metabolic syndrome in older adults of Chinese major cities. Diabetes Res Clin Pract. 2009:84(1):27-33

17. Falahi E, Khalkhali Rad AH, Roosta S. What is the best biomarker for metabolic syndrome diagnosis? Diabetes Metab Syndr. 2015:9(4):366-72.
18. Hughes JT, O'Dea K, Piera K, Barzi F, Cass A, Hoy WE, et al. Associations of serum adiponectin with markers of cardio-metabolic disease risk in indigenous Australian adults with good health, diabetes and chronic kidney disease. Obes Res Clin Pract. 2016;10(6):659-72.

19. Satoh N, Naruse M, Usui T, Tagami T, Suganami T, Yamada K, et al. Leptinto-adiponectin ratio as a potential atherogenic index in obese type 2 diabetic patients. Diabetes Care. 2004;27(10):2488-90.

20. Gauthier A, Dubois S, Bertrais S, Gallois Y, Aube C, Gagnadoux F, et al. The leptin to adiponectin ratio is a marker of the number of metabolic syndrome criteria in French adults. J Metab Syndr. 2011;31:1-6.

21. Oda N, Imamura S, Fujita T, Uchida Y, Inagaki K, Kakizawa $H$, et al. The ratio of leptin to adiponectin can be used as an index of insulin resistance. Metabolism. 2008;57(2):268-73.

22. Ayina CNA, Noubiap JJN, Etoundi Ngoa LS, Boudou P, Gautier JF, Mengnjo MK, et al. Association of serum leptin and adiponectin with anthropomorphic indices of obesity, blood lipids and insulin resistance in a subSaharan African population. Lipids Health Dis. 2016;15. http://www.ncbi. nlm.nih.gov/pmc/articles/PMC4869296/. Accessed 23 Sep 2016.

23. World Health Organization. Obesity: preventing and managing the global epidemic. Geneva: World Health Organization; 2000.

24. WHO Expert Consultation. Waist circumference and waist-hip ratio. Geneva: World Health Organization; 2011.

25. Okorodudu DO, Jumean MF, Montori VM, Romero-Corral A, Somers VK, Erwin PJ, et al. Diagnostic performance of body mass index to identify obesity as defined by body adiposity: a systematic review and metaanalysis. Int J Obes (Lond). 2010;34(5):791-9.

26. Alberti KG, Eckel RH, Grundy SM, Zimmet PZ, Cleeman JI, Donato KA, et al. Harmonizing the metabolic syndrome: a joint interim statement of the international diabetes federation task force on epidemiology and prevention; national heart, lung, and blood institute; american heart association; world heart federation; international atherosclerosis society; and international association for the study of obesity. Circulation. 2009:120(16):1640-5.

27. Von Frankenberg AD, do Nascimento FV, Gatelli LE, Nedel BL, Garcia SP, de Oliveira CS. Major components of metabolic syndrome and adiponectin levels: a cross-sectional study. Diabetol Metab Syndr. 2014;6:26

28. Kotani K, Sakane N. Leptin: adiponectin ratio and metabolic syndrome in the general Japanese population. Korean J Lab Med. 2011;31(3):162-6.

29. van Zyl S, van der Merwe LJ, van Rooyen FC, Joubert G, Walsh CM. The relationship between obesity, leptin, adiponectin and the components of metabolic syndrome in urban African women, Free State, South Africa. South Afr J Clin Nutr. 2017;30(3):68-73. doi:10.1080/16070658.2017.12673 80

30. Nour-Eldine W, Ghantous CM, Zibara K, Dib L, Issaa H, Itani HA, et al. Adiponectin attenuates angiotensin Il-induced vascular smooth muscle cell remodeling through nitric oxide and the RhoA/ROCK Pathway. Front Pharmacol. 2016;7. http://journal.frontiersin.org/article/10.3389/ fphar.2016.00086/abstract. Accessed 28 Nov 2016.

31. Chou H-H, Hsu L-A, Wu S, Teng M-S, Sun Y-C, Ko Y-L. Leptin-to-adiponectin ratio is related to low grade inflammation and insulin resistance independent of obesity in non-diabetic Taiwanese: a cross-sectional cohort study. Acta Cardiol Sin. 2014;30(3):204-14.

\section{Submit your next manuscript to BioMed Central and we will help you at every step:}

- We accept pre-submission inquiries

- Our selector tool helps you to find the most relevant journal

- We provide round the clock customer support

- Convenient online submission

- Thorough peer review

- Inclusion in PubMed and all major indexing services

- Maximum visibility for your research

Submit your manuscript at www.biomedcentral com/submit
Ciomed Central 